\title{
OBITUARY
}

\section{YAKOV VUL'FOVICH RASHKES}

(1932-1993)

The sudden death of Yakov Vul'fovich Rashkes, Doctor of Chemical Sciences, occurred on October 9, 1993. A prominent scientist in the field of the mass spectrometry of natural compounds has departed this life. Ya. V. Rashkes was born in Khar'kov on November 29, 1932. After graduating from the Central Asian State University, he began his working life as a labortory assistant. His scientific activity in the Institute of the Chemistry of Plant Substances [IKhRV], Academy of Sciences of the Uzbek SSR, in the then new field of vibrational spectroscopy began in 1959. As well as successfully defending his Candidate's dissertation in 1964, he prepared a handbook for chemists "The Main Applications of UV Spectroscopy to Organic Chemistry" [in Russian] (Fan, Tashkent, 1963). His many-sided talent enabled him subsequently to switch his interest to the methods of organic mass spectrometry. The subject of his Doctoral dissertation "The Mass Spectra of Alkaloids and Cardenolides" [in Russian] (1975) was a fundamental generalization of the laws of breakdown under electron impact of several types of biologically active compounds. He was the first to discover the mechanism of the Claisen rearrangement for quinoline alkaloids under mass-spectrometric conditions, and he also made an all-round study of the influence of the nature of substituents at $\mathrm{C}_{1}, \mathrm{C}_{6}, \mathrm{C}_{7}$, and $\mathrm{C}_{8}$ on the fragmentation processes of lycoctonine alkaloids of the diterpene series.

Ya. V. Rashkes belonged to the category of scientists with a high creative potential and with a wide range of interests. On his initiative, work was begun in IKhRV in the field of the metabolism of drugs, the rapid analysis of micro samples of plant raw material and of secondary metabolites of the organs of the cotton plant, and many others.

Ya. V. Rashkes also proved himself as a tutor of scientific specialists, preparing four Candidtaes of Science. He was one of the authors of the symposium "Mass Spectra of Organic and Organometallic Compounds" [in Russian] (Bashkir Branch of the Academy of Sciences of the USSR, Ufa, 1987) and published more than 200 papers.

The bright memory of a good, decent, and sympathetic man and a scientist with a capital S, Yakov Vul'fovich Rashkes, will always remain in our hearts.

Translated from Khimiya Prirodnyk Soedinenii, No. 3, p. 449, May-June, 1994. 